REsumo
Desenvolvemos a tese de que o
ensino de língua vem perdendo
sua capacidade de fažer laços
discursivos em decorrência da
ruptura da cadeia dos significan-
tes que sustentam o discurso do
professor, ocasionada pela mul-
tiplicação das demandas sociais
que recaem sobre o docente. Le-
vanta-se a hipótese de que os
cursos de licenciatura estejam
passando por mutações seme-
lhantes. Propõe-se que, a fim de
evitar esse destino, a formação
de professores deveria conduzir
o estudante à histerização do
discurso e, posteriormente, ao
Discurso do Mestre. Esse per-
curso é exemplificado por meio
da análise de excertos de ver-
sões sucessivas de uma mono-
grafia escrita por uma aluna de
Letras.
Descritores: escrita; discur-
so; licenciaturas.
tur

\title{
PROCURAM-SE PROFESSORES HISTÉRICOS: SOBRE O PAPEL DA ESCRITA NAS LICENCIATURAS
}

Thomas Massao Fairchild

\section{O discurso como laço}

A

universidade brasileira tem se expandido em grandes proporções nas últimas duas décadas. Essa expansão deu-se de forma mais acentuada no âmbito das instituições privadas durante os anos 1990 (Pietri, 2005, p. 43), mas ao longo da última década tem se dado também na esfera pública, sobretudo na rede federal. Dentro desse quadro, o aumento da oferta de vagas em cursos de licen- 
ciatura e a diversificação dos modelos de formação em nível superior podem estar configurando um panorama preocupante: a universidade, cada vez mais, vê-se em uma posição similar àquela ocupada pela escola nos anos 1960 e 1970, quando a quantidade de vagas na Educação Básica foi tremendamente incrementada. Uma das consequências desse boom de matrículas foi uma mudança geral no perfil dos alunos, expressa nas palavras de Geraldi: "De repente, não damos aulas só para aquelas que pertencem a nosso grupo social. Representantes de outros grupos estão sentados nos bancos escolares. E eles falam diferente" (2004, p. 43).

Este estranhamento do professor diante dos alunos que encontrava em sua sala pode estar se repetindo, hoje, na universidade. O trecho abaixo, extraído do projeto pedagógico de um curso de Letras, expressa a percepção de algum desarranjo entre o discente que seria esperado no Ensino Superior e o que tem chegado aos seus bancos:

O aluno, ao ingressar no Curso de Letras, apresenta, via de regra, em seu desempenho acadêmico, lacunas oriundas de sua formação no Ensino Fundamental e Médio, como demonstram os resultados do SAEB (2005) e do PISA. Ademais, nos últimos anos, os classificados em Letras por meio de processo seletivo têm apresentado resultados bem abaixo da média dos outros cursos da [universidade]. É necessário, portanto, oferecer condições para que os alunos com mais dificuldades alcancem rapidamente o nível desejado para ter um melhor aproveitamento no curso escolhido.

Tanto Geraldi quanto o projeto pedagógico acima parecem tratar da mesma questão. Valendo-nos de termos da psicanálise para tentar elucidar o que se passa, formulamos a seguinte hipótese: o dilema que as instituições de ensino vivem diante da ampliação das oportunidades de acesso a elas e das contradições que caracterizam a sociedade brasileira consiste no fato de que elas têm sido levadas a confrontar-se com subjetividades que não fazem laço facilmente com seus discursos tradicionais.

"Fazer laço" é, com efeito, o atributo central que Lacan reputa ao "discurso". O discurso define-se para Lacan como o mecanismo que instaura e mantém algum tipo de laço entre dois seres. Em seu seminário 17, Lacan (1992) sistematizou quatro modalidades desse laço, que ele chamou de "quatro discursos". Cada discurso, por sua vez, funcionaria com base em quatro elementos, representados por letras: $\mathrm{S}_{1}$, o significante-mestre; $\mathrm{S}_{2}$, o saber; $a$, o mais-gozar; e $\$$, o 
sujeito barrado. Esses elementos manteriam entre si uma ordem fixa e poderiam ocupar alternadamente uma de quatro posições: a do agente, a do outro, a da produção e a da verdade. Conforme cada uma das quatro letras ocupasse uma posição (definindo, portanto, as posições das demais), ter-se-ia configurado um discurso. Ao todo, portanto, quatro: o Discurso do Mestre, tendo $\mathrm{S}_{1}$ como agente; o Discurso Universitário, tendo $\mathrm{S}_{2}$ como agente; o Discurso do Analista, tendo a como agente; e o Discurso da Histérica, tendo \$ como agente.

Vale lembrar que esses arranjos expressam as formas como um laço discursivo pode funcionar, isto é, a estrutura que dá condição para que as significações ocorram. Esta consideração é importante porque o estranhamento que marca a relação entre professor e aluno pode ser pensado como uma falha em instaurar algum arranjo discursivo, fazendo com que o que se faz em sala de aula não faça mais sentido.

Neste trabalho, discutiremos a perda de sentido do ensino por meio da hipótese de uma ruptura da cadeia do saber $\left(\mathrm{S}_{2}\right)$. Igualmente, falaremos das possibilidades de instauração de novos laços por meio de um giro dos discursos, que relacionaremos ao conceito de "trabalho de escrita" (Riolfi, 2003, 2007).

\section{O sentido das licenciaturas}

A universidade, e particularmente as licenciaturas, começam a sentir as consequências de uma série de mutações que já atingiram a escola e afetaram o seu funcionamento. Dentre os muitos fatores que poderiam ser responsabilizados por essas mutações, interessam-nos aqueles que resultaram na necessidade de o professor tratar de questões a princípio externas à sua área de formação - como algumas tentativas de trabalhar com "temas transversais" e outros assuntos considerados importantes ou impostos por lei, que muitas vezes resultam em projetos que mobilizam toda uma escola e, ao fazer isso, interrompem o andamento normal das disciplinas sem de fato instaurar um campo de interdisciplinaridade.

Intervenções como essas certamente visam a algum objetivo justo - procuram instaurar um discurso que supostamente 
interessaria aos processos de escolarização. Desconsideremos os casos em que essas inserções se reduzem a práticas publicitárias de empresas que investem na formação de seus consumidores desde cedo - como palestras, feiras e outros eventos promovidos por jornais, editoras, empresas de produtos infantis variados. Desconsideremos também os casos em que essas inserções resultam da tentativa honesta de se flexibilizar os currículos e dinamizar a formação dos alunos. O que há na base desse tipo de situação é o fato de que ela pode resultar em interrupções sucessivas do que se estava fazendo. Começa-se a estudar um tópico, mas suspende-se o assunto por causa da semana da cultura, depois por causa da chegada de um estagiário, depois por conta de uma greve... No limite, corre-se o risco de que, sem conseguir mais achar o eixo em torno do qual gira sua profissão, o professor perca o norte - porque se instaura uma ruptura na cadeia dos significantes.

Se isto de fato acontece, trata-se de um problema bastante grave, pois uma quebra na cadeia dos significantes resulta na perda do laço discursivo que a escola mantém com aqueles a quem atende. Como a cadeia dos significantes representa, para Lacan, a trama dos conhecimentos socialmente estruturados, podemos dizer que $\mathrm{S}_{2}$ é o que permite que saibamos, por exemplo, como terminar uma frase que comece com "quem descobriu o Brasil foi..." ou "a raiz quadrada de
16 é...". Se essa cadeia é rompida, a consequência natural é que aquilo que se apresenta como um saber pareça sem sentido - tanto para quem ouve quanto para quem diz.

Há, portanto, dois fatores que podem motivar a quebra de $\mathrm{S}_{2}$ e a diminuição da capacidade da escola de fazer laço com seus alunos: 1) a própria abertura da escola para alunos cujos saberes não ressoam com os da escola - alunos para quem a frase "quem descobriu o Brasil foi..." não faz sentido, mesmo que completa; e 2) o fato de que cada vez menos há tempo e oportunidade para se sustentar um trabalho estruturado sobre um determinado tema sem ser interrompido - por algum projeto, por alguma empresa, ou mesmo por algum desses alunos que, não encontrando o sentido na escola, talvez sequer percebam seus arroubos como interrupção de algo. Em outras palavras, podemos dizer que a incorporação de um novo alunado e a tentativa de fazer laço com ele por meio da diversificação das tópicas de trabalho não têm resultado em uma escola mais dinâmica, mas, pelo contrário, têm contribuído para a simples desarticulação das disciplinas tradicionais e sua substituição por fragmentos de discurso que não chegam a formar uma nova cadeia de saberes.

Lacan propõe, em sua teoria, quatro arranjos de discurso. Isso implica que, se um discurso pode funcionar estacionariamente em certa posição, por outro lado os discursos 
"giram", isto é, as configurações dos elementos que constituem um laço discursivo mudam de função. É desses "giros" que resulta o que podemos chamar de produção de conhecimento, inclusive no sentido que essa expressão assume no contexto da Educação.

A reestruturação da cadeia significante $S_{2}$, que daria consistência a um discurso escolar renovado, exigiria, portanto, uma mobilização que anulasse, ao menos temporariamente, a função do Discurso Universitário. Defenderemos que essa mobilização consiste em uma conversão do Discurso Universitário, agenciado por $\mathrm{S}_{2}$, para o Discurso da Histérica, agenciado por $\$$ (o sujeito do desejo inconsciente), e finalmente para o Discurso do Mestre, agenciado por $\mathrm{S}_{1}$ (o significante-mestre). Isto é, para a estruturação de uma nova cadeia de saberes, seria preciso que o discurso das universidades nem sempre operasse a partir do lastro de saberes que, segundo a posição defendida aqui, tem sua solidez cada vez menos garantida, mas a partir dos excedentes de incompreensão que a leitura de qualquer texto gera - o objeto "a". No trecho abaixo, Revah descreve os termos dessa situação:

Nessa forma de comunicação que é própria do discurso Universitário ... os alunos estão no lugar do trabalho e trabalham de um modo que na teoria concerne ao chamado objeto "a". O que isso quer dizer? Esse objeto é da ordem do que não se deixa capturar, do que escapa e resta em toda operação discursiva. Podemos pensar então que nessa posição, na posição do aluno, este realiza um trabalho no qual algo é amarrado sem que essa amarração se complete, porque algo sempre escapa... O que esse discurso então articula como a sua produção é o sujeito do desejo, o sujeito dividido, um sujeito com questões e dúvidas, mas que não ficam à vista, conforme sugere o aparelhinho de Lacan, no qual o sujeito dividido (\$) encontra-se do lado direito, embaixo, no lugar da produção, que é o que resulta dessa configuração discursiva, desse tipo de ligação social. Para que isso ocorra, para que essas questões e dúvidas apareçam, seria necessário um giro discursivo, de modo que o aluno se torne o agente do discurso. Esse giro, poderse-ia dizer, produz a histerização do discurso. (2008)

A histerização do discurso, no entanto, não é condição suficiente para a produção de uma nova cadeia de saberes - que o digam as histéricas. Jean Allouch toca neste ponto ao refutar a tese de que Freud teria "furtado" de suas pacientes a teoria da psicanálise, afirmando que o que a histérica produz "não consiste em uma teoria, e sim em produzir, dirigindo-se ao seu parceiro, a sugestão de que haveria realmente uma teoria" $(1995$, p. 21). Isto fica representado, no esquema de Lacan, pelo fato de $\mathrm{S}_{2}$ aparecer, no Discurso 
da Histérica, abaixo da barra do recalcamento. Em outras palavras: o saber produzido pelo discurso histérico não é uma teoria na medida em que não pode ser explicitado, pois permanece na condição de saber inconsciente.

O que interessa à escola e ao ensino em geral é que, pelo menos em alguns momentos, esse saber possa teorizar-se, passando para cima da barra horizontal e tornando-se objeto de manipulação do estudante. Conforme o esquema dos discursos de Lacan, isto envolveria, portanto, ainda outro giro. Veríamos então que a "subida" de $\mathrm{S}_{2}$ para cima da barra do recalcamento "empurraria" $\mathrm{S}_{1}$ para a posição de agente do discurso - o que significa dizer que a teorização de um saber não sabido por meio do Discurso do Mestre exige, como correlato, a intervenção de um significante que faça $U m$, atuando como borda que permita reestruturar a bateria dos significantes em uma nova rede coesa. ${ }^{1}$

No Discurso do Mestre, $\mathrm{S}_{1}$ pode ser pensado como o professor tomado em sua subjetividade, isto é, não em sua posição institucional, em sua função social (afinal, é justamente esta que teve seus tapetes puxados pelos consecutivos vetos à sua forma de agir), mas em sua constituição singular, como ser tocado por uma falta que pode representar-se, ainda que incompletamente, em um determinado significante. Um pouco mais adiante tentaremos ilustrar na prática esse giro dos discursos a partir de um trabalho de escrita, e veremos que $S_{1}$ pode ser, para o professor em formação, um elemento de uma teoria com a qual ele se identifica e que passa a reorganizar sua leitura dos textos que se encontram ao redor.

Estaríamos, portanto, diante da necessidade de um $\mathrm{S}_{1}$ que interviesse para recortar essa rede fragmentária de quase saberes e reorganizá-la, primeiramente, de forma coerente, para aí assentarse uma singularidade - um estilo, uma forma de compreender os conceitos e colocá-los na prática, uma posição que permitisse boas tomadas de decisão no aperto do cotidiano etc. Fairchild (2010) afirma que não dimensionamos bem a exigência social que colocamos sobre os ombros do professor ao pedir que ele negue o "ensino tradicional". Acontece que negar uma tradição não é fácil, e pode de fato tornar-se impossível se concordarmos com Dufour (2005), para quem a modernidade se caracteriza justamente pela "queda dos grandes Sujeitos" que poderiam fazer o papel de $S_{1}$ na estruturação dos discursos. Temos, portanto, duas facetas de um mesmo problema: a contínua fratura de $\mathrm{S}_{2}$ ocorre simultaneamente 
ao achatamento das figuras que poderiam representar a Lei e restaurar a ordem simbólica onde ela, por ventura, se rompe.

A esperança seria que, em algum lugar, um sujeito pudesse ser fundado na Lei para que, chegando a esse terreno "dessimbolizado" pela avalanche de teorias e prescrições que vem tomando a escola, pudesse exercer a função de $\mathrm{S}_{1}$ na operação do Discurso do Mestre, começando o trabalho de estruturação de um saber $\left(\mathrm{S}_{2}\right)$ em teorias e práticas renovadas pelo crivo de sua subjetividade.

Eis então que voltamos à questão das licenciaturas. Seria de se esperar que elas fossem o lugar onde este sujeito pode ser fundado pela alienação a um Outro, representado pelas tradições que mantêm de pé o discurso universitário. No entanto, as licenciaturas começam a ver seu terreno revolvido pelo mesmo tipo de avalanche que já comprometeu bastante a escola.

Tomemos como exemplo o Decreto $\mathrm{n}^{\circ} 5.626$, de 22 de dezembro de 2010, que institui a obrigatoriedade da oferta de LIBRAS como disciplina curricular em todos os cursos de licenciatura e do ensino de língua portuguesa escrita para surdos nas licenciaturas em Letras com habilitação em Língua Portuguesa. Não se trata de discutir as intenções por trás dessa medida, mas de se pensar os efeitos práticos que o decreto pode vir a ter. Uma análise de currículos de cursos de Letras aponta uma tendência bastante clara: LIBRAS, em geral, é introduzida na forma de uma disciplina única, com carga horária que varia de 60 a 80 horas. $^{2}$ Ora, a finalidade de se ensinar LIBRAS a um professor de português seria que este professor, podendo ter em sua sala um aluno surdo, seja capaz de comunicar-se com ele. Mas quem saberá comunicar-se em LIBRAS graças a 80 horas de aula?

Eis, portanto, o quadro geral, no qual apontamos a possibilidade de que os cursos de formação de professores estejam perdendo a força que seria necessária para formar os sujeitos requisitados para atuar em uma escola em que os laços discursivos encontram-se fragilizados e em que se torna cada vez mais urgente a restauração de figuras que atuem como significante-mestre, dando algo em nome de que o professor possa erigir-se em sua função.

A hipótese que esboçamos aqui é a de que isso é possível por meio de um certo giro que saia de um Discurso Universitário fragilizado pelo afrouxamento de $\mathrm{S}_{2}$ por meio de uma histerização 
do discurso, e termine, enfim, no achado de um $\mathrm{S}_{1}$ que permita ao professor atuar como agente do Discurso do Mestre. Trabalhando com professores em formação em um curso de licenciatura em Letras, temos buscado concretizar esse percurso por meio de um tratamento específico da escrita. Passaremos a tratar disso em mais detalhe agora.

\section{Escrita de licenciandos em Letras}

Em se tratando de escrita, digamos que a situação de um licenciando em Letras é a seguinte: ao longo de seu curso, ele se vê instado a produzir uma escrita pautada em padrões que lhe são novos. Dentre esses padrões, incluem-se a necessidade de prestar contas diante do que já foi escrito por outros - as obras seminais, a produção mais atual sobre certos temas, os comentários dos professores em aula etc. Inclui-se também um conjunto de instruções sobre como formatar o produto de sua escrita, seja conforme normas técnicas, seja conforme as características mais comuns dos gêneros acadêmicos. Podemos designar esses padrões como modelos que serviriam de norte na aprendizagem do estudante.

Tomando a escrita numa concepção lacaniana, resta-nos dizer que "escrita" não coincide exatamente com 
produção de textos, e, portanto, apropriar-se de modelos através da escrita não significa exatamente o mesmo que aprender a fazer textos acadêmicos. A escrita, na perspectiva que adotamos, é um trabalho que está relacionado ao escrito, isto é, ao que reside na instância da letra no inconsciente. Podemos então dizer que a escrita, num curso superior, inicia-se pelo enlaçamento do sujeito no Discurso Universitário, representado pelo momento em que o aluno tem diante de si modelos explícitos aos quais tenta se aproximar. Como diz Lacan, em todo caso, “o que conduz ao saber não é o desejo de saber. $\mathrm{O}$ que conduz ao saber é ... o discurso da histérica" (1992, p. 22). Para nós, isso significa que um profissional de Letras não se forma enquanto agir movido pelo desejo de apropriar-se das figuras que toma como modelo. Para formar-se, é preciso realizar uma leitura histerizada dos modelos que se lhe apresentam.

Uma leitura histerizada é diferente de uma leitura de estudos propriamente dita, pois enquanto esta procura saber da melhor forma possível “o que o texto quis dizer”, aquela procura determinar "o que o texto quis ao dizer". A leitura histerizada é o primeiro passo para o trabalho de escrita que propomos. $\mathrm{O}$ segundo passo é a instauração de uma borda, que, nos casos que nos interessam, expressa-se pelo fato de o aluno localizar, entre as referências que lhe são dadas, uma referência que lhe dê a maneira de ler todas as demais.

Vejamos isto de forma concreta. O primeiro exemplo que apresentamos serve para ilustrar o funcionamento do Discurso Universitário. Como afirmamos que uma reestruturação do ensino requer que se saia do Discurso Universitário, vamos ilustrar aqui como ele pode funcionar naquilo que contém de prejudicial, porque a prevalência de $\mathrm{S}_{2}$ faz uma teoria sobrepor-se à leitura do dado. Os dois excertos a seguir foram retirados de uma dissertação de mestrado em que a pesquisadora se propôs a elaborar, juntamente com uma professora de um curso de Letras, algumas atividades para uma disciplina voltada ao ensino da leitura e escrita. No primeiro trecho, ela discute uma decisão tomada pela professora.

(1) Foi perguntado, ainda aos alunos, que assuntos gostariam de estudar na disciplina Língua Portuguesa. A resposta foi condizente com a representação que os alunos fazem da aprendizagem da língua, na qual estudar português é aprender regras e nomenclaturas, pois na seleção dos assuntos cons- 
tam: letras e fonemas, verbos, ortografia, adjetivos, pronomes. Somente três alunos (L, $\mathrm{M}, \mathrm{F})$ afirmaram que gostariam de estudar texto, interpretação para escrever melhor e aprender a dar opinião.

Essas respostas serviram para que a pesquisadora e professora pensassem sobre as aulas a serem desenvolvidas, levaram também a decisão de que a gramática seria estudada no texto. (itálico nosso)

Interessa aqui notar que, conforme o trecho destacado, a pesquisadora afirma ter decidido sobre a forma de trabalhar gramática a partir do que escutou dos alunos. Em um caso como esse, diríamos que o que agencia o laço discursivo entre professor e alunos é a subjetividade dos alunos: estes são convocados a falar e, explicitando de alguma maneira suas demandas, colocam ao professor questões imprevistas do ponto de vista do conhecimento estruturado da disciplina $\left(\mathrm{S}_{2}\right)$. O fragmento acima mostra que, de fato, as respostas dos alunos divergiam do que havia sido planejado. Ao mesmo tempo, também evidencia o que se esperava do ponto de vista desse planejamento - "somente três alunos ... afirmaram que gostariam de estudar texto". Se esta fosse a situação, diríamos que se trata de um momento de histerização do discurso, em que as questões dos alunos exigem do professor acionar um "saber não sabido". O excerto abaixo, no entanto, faz-nos pensar que o ponto em que se ancora a decisão tomada pela professora não é a fala dos alunos.
(2) Certamente, o aluno não precisa aprender a nomenclatura gramatical, precisa, isto sim, aprender a usar a língua em diferentes situações para que possa ter liberdade de exercer a cidadania de forma mais plena, fazendo uso de uma língua enquanto sujeito socialmente constituído. Esta língua comporta uma gramática a serviço do discurso, na qual as questões de linguagem são solucionadas nas próprias situações sociais.

Nada na língua, em nenhuma língua, escapa a essa gramática. Por isso é que se diz que não existe língua sem gramática. Nem existe gramática fora da língua. Ou, ninguém aprende uma língua para depois aprender a sua gramática. Qualquer pessoa que fala uma língua fala essa língua porque sabe a sua gramática, mesmo que não tenha consciência disso (Antunes, 2007 , p. 26). ${ }^{3}$

Digamos que o excerto acima opera discursivamente como $\mathrm{S}_{2}$, na forma de uma bem-estruturada paráfrase de alguns dizeres que circulam na área, dando ao texto a feição que seria de se esperar em se tratando de um trabalho acadêmico. $\mathrm{O}$ que nos interessa pontuar é que é neste trecho, mais do que nas respostas dos alunos no momento da pesquisa relatado em (1), que encontramos as razões para "a decisão de que a gramática seria estudada no texto". Mais ainda, um reexame do excerto (1) mostra que a consulta aos alunos desde o início previa tanto as respostas que surgiriam quanto o fato de que elas não seriam ouvidas: basta aproximar o trecho em que a autora afirma que "a resposta foi condizente com a representação que os alunos faz̧em da apren- 
dizagem da lingua, na qual estudar português é aprender regras e nomenclaturas", em (1), e o trecho em que ela diz que "certamente, o aluno não precisa aprender a nomenclatura gramatical', em (2).

Eis, portanto, o problema de uma escrita fixada no Discurso Universitário: a prevalência de um dizer autorizado que se supõe suficiente para instaurar a significação pode interromper a escuta e fazer com que se ouça no dizer de um sujeito apenas aquilo que já se espera que ele diga.

O exemplo seguinte servirá para ilustrar que a aprendizagem nem sempre se inicia pelo Discurso Universitário, ou ainda, que nem sempre a apropriação de um modelo se dá pela sua apreensão como uma forma já imbuída de sentido. O excerto pertence à primeira versão de um projeto de pesquisa elaborado por uma aluna de Letras em 2009, antes de seu primeiro contato com o orientador.

(3) As práticas de leitura na $8^{a}$ série do ensino fundamental devem contribuir para a formação de um leitor-produtor de textos, na medida em que essas leituras levarem em conta os elementos constitutivos dos gêneros escolbidos, ampliando o conhecimento linguístico e a $v i$ são de mundo desses alunos.

Nesse sentido, serão observadas as estratégias de leitura e interpretação e se essas estratégias condizem com o contexto sociocultural dos alunos, se os textos são apresentados em diferentes suportes, com dinâmicas interessantes, despertando o interesse dos alunos ou se o acesso aos textos se dá primordialmente por meio do livro didático. Desse modo, será possível verificar se há um trabalho sistematizado com a leitura. Se aulas visam apenas os aspectos gramaticais de frases soltas, sem con- 
texto, se as concepcõos de leitura que os professores dizem ter é a mesma praticada por eles em sala de aula. (itálicos nossos)

Os trechos destacados mostram-nos o comparecimento, dentro deste trecho relativamente curto, de uma série de termos ou frases que - saiba a autora ou não - remetem a dizeres mais ou menos estabilizados na área pela qual ela começa a enveredar: 1) o postulado de que o objeto de ensino em língua portuguesa são os gêneros (sem remissão específica a nenhuma obra); 2) o postulado de que o ensino deve levar em conta a "visão de mundo" e o "contexto sociocultural dos alunos" (remetido a uma obra de Bordini \& Aguiar, ligados aos estudos do letramento); e 3) o postulado de que a leitura funciona com base no agenciamento de estratégias e não na aplicação de regras (que remete aos estudos de linha cognitivista, representados no trabalho por A. Kleiman). Há ainda pelo menos dois outros postulados que, embora não tenham um caráter teórico específico, comparecem ao trecho transcrito acima e consistem em críticas ao trabalho do professor: 4) a afirmação de que o ensino de gramática é insuficiente, por restringir-se ao nível da frase; e 5) a afirmação de que os discursos dos professores não condizem com suas práticas.

O que interessa notar é que, apesar de a presença dos postulados teóricos 1, 2 e 3 denotar certa consistência entre o texto da aluna e suas leituras, eles aparecem tomados um a um e relacionados entre si por operações de adição. $\mathrm{O}$ resultado disso é que, embora diferentes conceitos compareçam ao trabalho, a relação entre esses conceitos não chega a ser problematizada de forma explícita. A estudante parece pautar-se, antes, pela noção de que os conceitos se complementam, somando-se uns aos outros para preencher todos os espaços de reflexão provocados pelo problema de pesquisa.

A presença dos postulados 4 e 5 , que consistem em críticas ao ensino centradas na figura do professor, interessa também porque ela parece contribuir para uma certa desorganização do texto, levando a aluna a oscilar entre a focalização da pesquisa sobre o aluno ou sobre o professor, como vemos no trecho a seguir:

(4) Dessa forma, uma investigação é necessária sobre o que os alunos estão lendo na $8^{a}$ série e como estão lendo. De maneira superficial, aprofundada ou a leitura de textos só ocorre como pretexto para ensinar aspectos gramaticais. Como os professores se apropriam do material de leitura que dispõem. (itálicos nossos)

82 Estilos clin., São Paulo, v. 18, n. 1, jan./abr. 2013, 71-88. 
Enfim, a posição assumida pela aluna na produção desta primeira versão de seu projeto de pesquisa pode ser caracterizada por um duplo movimento. Por um lado está a dificuldade em realizar uma análise mais pontual do que se apresenta inicialmente como "grande tema" de sua pesquisa - a hipótese de que há problemas no ensino de leitura - e, assim, demarcar no seio de uma afirmação vaga o espaço individual a ser ocupado por seu trabalho. Por outro lado, está a tentativa de dar conta de todo o problema, que se traduz na ausência de escolhas teóricas (por exemplo, entre uma análise mais centrada no conceito de gênero, ou no de letramento, ou na perspectiva cognitivista) e metodológicas (pesquisar as práticas de leitura dos alunos ou as dos professores).

$\mathrm{O}$ que estes trechos citados nos mostram é uma fragmentação de $\mathrm{S}_{2}$ : em um texto repleto de referências e ideias para investigação, nenhuma delas é tomada como ponto de partida desde o qual significar as demais. Mais precisamente, o que parece faltar no texto em pauta, se não uma precoce clareza sobre as escolas de pensamento que compõem uma área de estudos, é o que poderíamos descrever como a simpatia da aluna por um ou outro dos textos lidos, por esta ou aquela linha teórica. Mesmo que a existência dessa "simpatia" fosse completamente desconhecida para a autora, é certo que ela poderia existir.

Isto que chamamos de "simpatia" poderia ser remetido à posição ocupada por \$ no Discurso Universitário: mesmo ao dar os primeiros passos na academia, um aluno já teria como acrescentar aos modelos que lhe são apresentados elementos de um saber inconsciente que pode fazer laço com o professor e com os textos da tradição de sua área, ainda que não consiga articular um discurso coerente sobre o que, exatamente, causa essa "simpatia".

O primeiro projeto desta aluna se encontra, portanto, fora de laço discursivo: seu texto se compõe pela transcrição de uma fraseologia lida ou escutada pelos corredores da universidade, justapostos sem uma articulação consistente. Se há aí uma escuta, ela captura o que ouve enquanto elemento do Real, repetindo-o à maneira daqueles pássaros miraculados da fantasia de Schreber - sem compreender o que as palavras dizem, mas transmitindo seu "veneno de cadáver" (Schreber, 1995, p. 189). Poderíamos dizer, enfim, que se trata de um texto sem borda, ao qual falta aquele elemento simbólico heterogêneo que faça às vezes de Um e organize a massa de dizeres disponíveis conforme uma lógica consistente.

Vejamos agora excertos de uma versão posterior do trabalho da mesma aluna, escrita em 2010, já quando ela estava em contato com um orientador.

(5) Vale ressaltar, que para que haja o $5^{\circ}$ nivel de leitura, é preciso que haja leitura desde o primeiro nivel, é necessário um acúmulo de memória por meio do interdiscurso que, para Orlandi apud (M. Pêcheux, 1990) é o conjunto daquilo que já foi dito e esquecido que determina o que será dito e no qual está respaldada a possibilidade mesma do dizer. Para ele, "o gesto de leitura é uma disciplina que se 
aprende em conformidade com o discurso documental, a memória do arquivo", ou seja, "para que nossas palavras tenham sentido é preciso que já tenham sentido". Orlandi (p.59, 2008)

Filiamo-nos a redes de sentidos em um gesto de interpretação, na relação com a língua e a história, e em que trabalham a ideologia e o inconsciente. (M. Pêcheux, 1990, itálico nosso)

O ponto umbilical deste trecho é o deslocamento de um dos postulados recolhidos pela aluna da leitura de Bordini \& Aguiar - a descrição do que as autoras chamam de "quinto nível" de leitura. Este postulado, inicialmente apenas parafraseado no projeto de 2009, é agora recortado do lugar que ocupa na obra de origem, em que funciona como ponto fulcral de uma série de "níveis" de leitura, para receber um tratamento conceitual imprevisto, a partir de outra referência teórica.

O que acontece aqui é a subtração de um postulado de seu lugar original na obra de referência e sua reinscrição em outro terreno. Podemos considerar essa reinterpretação do conceito de "níveis de leitura" como uma histerização do discurso na medida em que o que interessa não é mais saber "o que o texto diz" $\left(\mathrm{S}_{2}\right)$, mas "em que medida posso ser desejado, enquanto leitor (\$), por esse texto". Trata-se, assim, de colocar em jogo a posição a partir da qual um texto propõe-se a ser lido enquanto cadeia estruturada de significantes e, dando um passo ao lado, questioná- lo no que ele traz como um saber não sabido.

Daí por diante, pode-se ver a reinscrição da autora em um discurso ao estilo universitário: as citações de Eni Orlandi e Michel Pêcheux encadeiam-se em uma espécie de aceleração metonímica, indicando mais uma vez a tentativa de recobrir o terreno de uma indagação com as palavras já enunciadas por outros.

O importante é que essa nova série de metonímias é desencadeada pelo que poderia ser chamado de uma "quebra de escrita" (Riolfi, 2007), que, se não tem a feição clássica de um lapso, representa minimamente a tomada do que antes se apresentava como signo, agora, como significante - portanto, passível de derivar para outra ordem de discurso. Nesse deslocamento está uma mudança no lugar de onde se lê a palavra do outro, que passa a ser tomada como portadora de um "espaço" que pode ser complementado por qualquer coisa advinda do próprio sujeito que escreve.

Isto é diferente do que a estudante fazia em seu primeiro projeto de pesquisa, no qual as palavras dos autores eram citadas por simples justaposição, numa aparente tentativa de recobrir o campo de pesquisa com signos cujo sentido estaria garantido pela universidade.

Pode-se dizer, portanto, que nesse ponto da escrita esboça-se um movimento pelo qual o sujeito que escreve faz um novo laço com aquilo que lê. O postulado do "interdiscur- 
so", isolado enquanto significante, passa a funcionar como $\mathrm{S}_{1}$ interpelado no lugar do Outro por um $\$$ que se reconhece, nesse movimento, enquanto sujeito barrado. Essa configuração, correspondente ao que Lacan caracteriza como o Discurso da Histérica, representa o ato pelo qual o sujeito toma a si mesmo como portador de uma indagação (no caso da histérica, o sintoma; no caso da pesquisadora, sua pesquisa), demandando do Outro uma resposta ao desejo que se encontra inacessível ( $a$ no lugar da verdade) - no caso da histérica, a interpretação; no caso da pesquisadora, os conceitos da Análise do Discurso que preenchem imaginariamente a lacuna aberta por sua interrogação.

Como afirmamos acima, em todo caso, o saber produzido por uma leitura histerizada não é ainda um conhecimento que possa ser enunciado de forma organizada, ganhando a forma de texto. A passagem para uma escrita mais autoral, conforme postulamos, requerer ainda outro movimento, de modo que aquilo que ocupa o lugar da produção no Discurso da Histérica possa sair da posição de recalque para exteriorizar-se na forma de texto manipulável.

Evidentemente, esse movimento não se dá de forma definitiva, mas podemos tentar ilustrá-lo a partir de um último excerto que sugere que, uma vez instaurando-se "interdiscurso", "Pêcheux", "Orlandi” ou "Análise do Discurso" como aquilo em nome 
de que farei minha pesquisa, a escrita da estudante em questão pode passar a operar, mesmo que momentaneamente, no Discurso do Mestre - o que nos parece vantajoso do ponto de vista da formação. Eis um exemplo:

(6) Segundo Bogdan e Biklen (1994), os questionários trazem consigo "a vantagem" de "não impor um contato direto ou mais prolongado com os sujeitos da pesquisa" A pesquisa "qualitativa permite interagir com os sujeitos" de forma menos invasiva e ameaçadora. Ora, se interagir pressupõe agir reciprocamente, como se pode conceber uma pesquisa qualitativa sem um contato direto com o sujeito? Então, o que é lido é apenas o código (a língua), não a linguagem: há apenas um texto pronto e acabado, mas não há interação propriamente dita. (itálicos da autora)

O trecho acima sugere que, uma vez realizada a histerização da leitura, a escrita permite aos poucos uma certa elaboração dos resultados do Discurso da Histérica, colocando o escritor em condições de falar "em nome" de algo. Este fragmento em particular mostra que a aluna desloca-se, passando a falar "em nome de Pêcheux", mas faz isso não apenas para parafrasear Pêcheux - pelo contrário, em Pêcheux ela encontra um lugar desde onde ler outros textos e elaborar uma posição sobre eles, inclusive tomando decisões como a de rechaçar certos postulados e aceitar outros.

À guisa de conclusão, pode-se dizer que essa "subida" de $\mathrm{S}_{2}$ na passagem do Discurso da Histérica para o Discurso do Mestre pode ser uma ilustração teórica do conceito de "trabalho de escrita" cunhado por Riolfi $(2003,2007)$. Vale notar que este processo é diferente de uma escrita que se pauta, desde o início, pela tentativa de apropriação de modelos. Fica então um alerta: até que ponto, ensinando futuros professores a reproduzir os conhecimentos que sustentam a função da universidade sem pôr de si no que fazem, estamos deixando-os em condições de enfrentar as demandas da escola contemporânea, que não cessa de pedir por sujeitos que, assumindo sua dívida com o Outro, possam restaurar a possibilidade de fazer laço com estes seres humanos a quem, pelo menos por enquanto, e felizmente, ainda chamamos de alunos? 


\begin{abstract}
We herein develop the thesis that language teachers are losing the ability to establish discoursive ties due to the breakdown of the chain of signifiers that sustains their discourse, caused by the increasing social demands that befall them. We sustain that teacher education courses might be undergoing a similar process. We propose that in order to prevent such fate teachers' education should cause future teachers to enter the Discourse of the Hysteric and, later on, the Master's Discourse. One such movement is illustrated by the analysis of excerpts from successive drafts of a paper written by a Language Arts senior.
\end{abstract}

Index terms: writing; discourse; teacher education courses.

SE BUSCAN PROFESORES HISTÉRICOS: SOBRE EL ROL DE LA ESCRITURA EN CURSOS DE PROFESORADO

\title{
RESUMEN
}

Se desarrolla la tesis de que la enseñanza de lengua viene perdiendo su capacidad de establecer lazos discursivos como consecuencia de la rotura de la cadena de significantes que sostiene el discurso del profesor, ocasionada por la multiplicación de demandas sociales que recaen sobre él. Se plantea la hipótesis de que los cursos de profesorado estén pasando por mutaciones semejantes. Para que se lo evite, se propone que la formación de profesores debe conducir al estudiante a la histerización del discurso y, posteriormente, al Discurso del Maestro. Dicho recorrido se ejemplifica con el análisis de fragmentos de versiones sucesivas de una monografía escrita por una estudiante de Letras.

Palabras clave: escritura; discurso; profesorado.

\section{REFERÊNCIAS}

Allouch, J. (1995). Letra a letra: transcrever, traduzir, transliterar (D. D. Estrada). Rio de Janeiro: Campo Matêmico.

Dufour, D.-R. (2005). A arte de reduz̧ir as cabeças: sobre a nova servidão na sociedade ultraliberal (S. R. Felgueiras, Trad.). Rio de Janeiro: Companhia de Freud.

Fairchild, T. M. (2010). Passar pelo escrito: a formação de professores para um novo século. Anais do ENDIPE - Encontro Nacional de Didática e Prática de Ensino, 15 (pp. 2550-2562). Belo Horizonte: UFMG.

Geraldi, J. W. (2004). Concepções de linguagem e ensino de português. In J. W. Geraldi (Org.) O texto na sala de aula (3a ed., pp. 39-46). São Paulo: Ática.

Lacan, J. (1992). O seminário, livro 17: o avesso da psicanálise (A. Roitman, Trad.). Rio de Janeiro: Jorge Zahar.

Nasio, J.-D. (1993). Cinco lições sobre a teoria de Jacques Lacan (V. Ribeiro, Trad.). Rio de Janeiro: Jorge Zahar. 
Pietri, E. (2005). Concepções de língua e escola e propostas de ensino de língua portuguesa: discussões sobre reprodução/transformação social. Falla dos Pinhaes, 2(2), 35-52.

Revah, D. (2008). A arte de educar e os giros do discurso. Anais do Colóquio LEPSI. Formação de profissionais e a criança-sujeito, 7. Recuperado em 23 de abril, 2011, de SciELO proceedings (Scientific Electronic Library online): http://www.proceedings.scielo.br/ scielo.php?script=sci_arttext\&pid=MSC0000000032008000100026\&lng $=$ en\&nrm $=$ abn

Riolfi, C. R. (2003). Ensinar a escrever: considerações sobre a especificidade do trabalho de escrita. Leitura. Teoria \& Prática. Revista da Associação de Leitura do Brasil, 40, 47-51.

Riolfi, C. R. (2007). Quebras na escrita, surpresas para quem escreve: o percurso subjetivo na formação do professor de Língua Portuguesa. In E. Calil (Org.), Trilhas da escrita: autoria, leitura e ensino (pp. 33-64). São Paulo: Cortez.

Schreber, D. P. (1995). Memórias de um doente dos nervos (M. Carone, Trad.). Rio de Janeiro: Paz e Terra.

\section{NOTAS}

1 Sobre a relação entre borda, rede de saberes e furo, remeto o leitor ao esquema da "matriz da estrutura" elaborado por J.-D. Nasio (1993, p. 65).

2 Conforme os dados preliminares da pesquisa "Licenciaturas em Letras: representações e práticas na formação profissional docente”, sob minha coordenação, atualmente desenvolvido na Universidade Federal do Pará.

3 Mantenho na transcrição do dado a redação e formatação originais do trabalho analisado.

tmfairch@yahoo.com.br Av. Marquês de Herval, 668/401 66085-311 - Belém - PA - Brasil. 